\title{
Doğu Karadeniz Subpopulasyonunda Ağız Kanseri Bilgi Düzeyi ve Farkındalığının Değerlendirilmesi
} Assessment of Oral Cancer Knowledge Level and Awareness in Eastern Black Sea Subpopulation

\section{Dilara Nil Tomrukçu, Taha Emre Köse}

Recep Tayyip Erdoğan Üniversitesi Diş Hekimliği Fakültesi Ağız, Diş ve Çene Radyolojisi Anabilim Dalı, Rize, Türkiye

\begin{abstract}
Özet: Ağız kanseri birçok risk faktörü ile ilişkili ortaya çıkar ve diğer kanser türleri gibi görülme sıklığı gün geçtikçe artan bir kanser türüdür. Önlenebilmesi ve erken teşhis yardımıyla kolayca tedavi edilebilmesi için hastaların bu konu hakkında bilgi sahibi olması gerekmektedir. Bu çalışmada; Rize ilinde bulunan hastaların ağız kanseri hakkındaki bilgi düzeyi ve farkındalığının değerlendirilmesi amaçlanmıștır. Araștırma toplam 251 gönüllü hasta üzerinde, yüz yüze anket formu doldurularak yapılmıștır. Bu anket içerisinde yaș, cinsiyet, eğitim seviyesi, sigara ve alkol kullanımı, ailede kanser hikayesi varlığı gibi kişisel soruların yanında; ağız kanseri bilgi düzeyi ölçme amaçlı 16 adet soru sorulmuştur. Veriler, SPSS programı ile istatistiksel olarak analiz edilmiştir. Tüm katılımcılar değerlendirildiğinde bilgi düzeyi sorularında ortalama doğru cevap sayısı 12 olarak bulunmuștur. Yaşla birlikte toplam bilgi düzeyi arasında ters yönlü anlamlı bir ilişki saptanmıştır. $(\mathrm{p}<0,05)$. Ailesinde kanser hikayesi olan hastaların bilgi düzeyi olmayan hastalarla karşıllaştırıldığında anlamlı fark saptanmamıştır. Diş hekimi/doktorlardan ağız kanseri hakkında danışmanlık alan hastaların bilgi düzeyi yüksek bulunmuştur (p<0,05). Bilgi soruları arasında en çok sigara kullanımının, en az ise sebze ve meyveden fakir beslenmenin ağız kanserine neden olduğu doğru olarak bilinmiștir. Sigara kullanmayan ve ağız bakımı iyi olan hastaların bilgi düzeyi daha yüksek olarak bulunmuștur ( $\mathrm{p}<0,05)$. Aktif sigara kullanan ve sigara kullanıp bırakmış hastalar arasında toplam bilgi düzeyi bakımından anlamlı fark bulunamamıştır ( $\mathrm{p}>0,05)$. Alkol kullanan hastaların kullanmayan hastalara göre alkolün ağız kanseri için risk faktörü oluşturduğu bilgisinin daha yüksek olduğu görülmüştür (p<0,05). Hastalar ağız kanserlerinin etiyolojik faktörleri ve belirtileri açısından bilgilendirilmeli, ağız kanserini önleyici adımlar atılmalıdır.
\end{abstract}

Anahtar Kelimeler: Ağız kanseri; bilgi; farkındalık; risk faktörleri

Abstract: As an increasing type of cancer, oral cancer is associated with many risk factors. It is necessary for patients to have information about this subject to be prevented and easily treated with the help of early diagnosis. This study aims to evaluate oral cancer patients' knowledge and awareness in Rize population. The study was conducted on total of 251 volunteer patients, filling in a face to face questionnaire. Besides personal questions, 16 questions were asked to measure oral cancer knowledge level. The data were analyzed with SPSS program. The average number of correct answers was found 12. An inverse significant relationship was found between age and total knowledge level $(\mathrm{p}<0.05)$. No significant difference was found in knowledge level of patients with a family history of cancer compared to without a family history. The knowledge level of patients who received oral cancer counseling from doctors was found to be high ( $\mathrm{p}<0.05)$. It was correctly known that smoking was the most common cause and the least was nutritionally poor diet. The knowledge level of nonsmoker patients with good oral care was found to be higher $(\mathrm{p}<0.05)$. No significant difference was found between active smokers and smokers who quit smoking ( $>>0.05$ ). It was seen that alcohol use was a risk factor for oral cancer compared to patients who did not use alcohol $(\mathrm{p}<0.05)$. Patients should be informed about the etiological factors and symptoms of oral cancers and preventive measures should be taken.

Keywords: Awareness; knowledge; oral cancer; risk factors

ORCID ID of the authors: D.N.T0000-0002-9607-6362, T.E.K 0000-0003-3601-0393

\author{
$\begin{array}{llll}\text { Received } 16.07 .2020 & \text { Accepted } 20.08 .2020 & \text { Online published } 24.09 .2020\end{array}$
}

Correspondence: Dilara Nil TOMRUKÇU- Recep Tayyip Erdoğan Üniversitesi Diş Hekimliği Fakültesi Ağız, Diş ve Çene Radyolojisi Anabilim Dalı, Rize, Türkiye email: dt.dilaranil@gmail.com 


\section{Giriş}

Dudak, dil, ağız tabanı, damak, dişeti, alveoler mukoza, yanak mukozası veya orofarinksi etkileyen kanser türü olan ağız kanseri Dünya Sağlık Örgütü tarafından en sık karşılaşılan 6 . kanser türü olarak belirtilmektedir (1). Yeni $\tan 1$ ve tedavi yöntemleri gelişmesine rağmen, 5 y1llık hayatta kalma oranına bakıldığında en düşük kanserlerden biridir (2). Bunun başlıca sebebi olarak; malign lezyonların erken teşhis edilememesi gösterilmektedir. Geç dönemde teşhis edilen ağız kanserleri cerrahilerinin agresif olması sonucu morbiditelerinin yüksek olduğu bilinmektedir (3). İnsanlardaki kanserlerin \%4-5'ini ağı kanserleri oluşturmaktadır (4). Lokalize tümör varlığında ilk 5 y1l hastanın sağ kalım oranı \%80 iken, metastaz varlığında ise ilk 5 yıl sağ kalım oranı \%40'a düşmektedir (5). Ağı boşluğu vücudun en kolay ulaşlabilen, herhangi bir cihaz gerektirmeden sadece göz ile muayenesi yapılabilen bir bölgesi olmasına karşın, ağız kanseri yalnızca \%26-48 oranında erken teşhis edilebilmektedir (1).

Ağız kanseri etiyolojisi multifaktöriyeldir; sigara ve tütün mamüllerinin tüketimi, alkol tüketimi, uygun yapılmamıș dental restorasyonlar, Human Papilloma Virüs (HPV), sebze ve meyveden fakir beslenme alışkanlığı, bağışıklık sisteminin düşük olmasina neden olan faktörler (AIDS vs.), kötü ağız hijyeni, genetik yatkınlık, güneş 1şınına maruziyet, Güneydoğu Asya Bölgesi'ne özgü betel yapră̆ 1 çiğneme alışkanlığı bunlar arasında bulunmaktadır (6).

Ağız kanseri çok farklı şekillerde belirti verebilir. Bunlar; ağızda iyileşmeyen ülserler/ çekim soketleri, lökoplaki benzeri beyaz yama, eritroplaki benzeri kırmızı yama, kombine kırmızı-beyaz yama şeklinde lezyonlar (eritrolökoplaki), çiğneme ve yutma güçlüğü veya ağrı (disfaji), kulak ağrısı, ağız açıklığının sınırlanması (trismus), konuşma değişikliği (dizartri), hissizlik gibi duyu değişikliği veya karıncalanma hissi (parestezi), servikal lenf nodu büyümesi (adenopati), diș hareketliliği veya protezin uyumunda değişiklik, dişlerde ağrı, mobilite, kemik ve diş kaybı, ağız kuruluğudur $(7,8)$.
Bu çalıșmada; Rize ilinde bulunan hastaların ağız kanseri hakkındaki bilgi düzeyi ve farkındalığının değerlendirilmesi amaçlanmıştır.

\section{Gereç ve Yöntemler}

Çalışma için gerekli etik kurul onayı, Recep Tayyip Erdoğan Üniversitesi Tip Fakültesi Bilimsel Araştırmalar Etik Kurul Başkanlığı'ndan (2020/126) alınmıştır.

$\mathrm{Bu}$ araştırmaya ait veriler Recep Tayyip Erdoğan Üniversitesi Diş Hekimliği Fakültesi Ağız, Diş ve Çene Radyolojisi Ana Bilim Dalı'na dental muayene amaciyla başvurmuş toplam 251 gönüllü hasta üzerinde, yüz yüze anket formu doldurularak elde edilmiştir. Araştırmaya zihinsel engeli olmayan, ağız kanseri tanısı konmamış, 18 yaş üstü rastgele seçilmiş gönüllü hastalar dahil edilmiştir. Araştırmaya katılan hastaların isim-soy isim belirtilmeden cevap gizliliği güvence altına alınmıştır. Çalışmaya katılan hastalara ağız kanserleri ile ilgili herhangi bir ön bilgi verilmemiştir.

$\mathrm{Bu}$ anket içerisinde yaş, cinsiyet, eğitim seviyesi, sigara ve alkol kullanımı alışkanlığı, ailede kanser hikayesi varlığı, oral hijyen değerlendirmesini sağlayan demografik ve kişisel soruların yanında; ağız kanseri bilgi düzeyi ölçme amaçli 16 adet soru sorulmuştur.

İstatistiksel değerlendirmede SPSS 23 (SPSS Inc, Chicago, IL, USA) programı kullanılmış, güven aralığ $1 \% 95(p>0,05)$ olarak seçilmiștir. Tek yönlü varyans test olan ANOVA ve bağımsız örneklem t-testi kullanılmıştır.

\section{Bulgular}

Araştırmaya katılan hastaların demografik özellikleri Tablo 1'de verilmiştir. Yaş aralığ 1 $18-75$ ve ortalama yaşı $36,40 \pm 15,9$ olan kat1limciların \%50,6's1 (n=127) kadın ve $\% 49,4$ 'ü $(\mathrm{n}=124)$ erkek hastadır. 
Tüm katılımcılar değerlendirildiğinde mevcut 16 adet bilgi düzeyi sorusunda ortalama doğru cevap sayıs1 12 olarak bulunmuştur. Katılımcıların ağız kanserinin risk faktörleri ile ilgili sorulara verdikleri cevapların dağılımı Tablo 2'de, ağız kanserinin belirtileri ile ilgili sorulara verdikleri cevapların dağılımı ise Tablo 3'de verilmiştir.

Tablo 1. Çalışmaya katılan hastaların demografik verileri.

\begin{tabular}{lll}
\hline Değişkenler & & $\mathbf{n}(\%)$ \\
\hline \multirow{2}{*}{ Cinsiyet } & Kadın & $127(\% 50.6)$ \\
Yaş & Erkek & $124(\% 49.4)$ \\
& $17-24$ & $74(\% 29.5)$ \\
& $25-34$ & $47(\% 18.7)$ \\
Eğitim durumu & $35-50$ & $84(\% 33.5)$ \\
& $50+$ & $46(\% 18.3)$ \\
& İlkokul mezunu & $78(\% 31.2)$ \\
Sistemik hastalık varlığı & Lise mezunu & $94(\% 37.6)$ \\
& Universite mezunu & $66(\% 26.4)$ \\
Sigara içme alışkanlığı & Yüksek lisans/ doktora mezunu & $12(\% 4.8)$ \\
& Var & $44(\% 17.5)$ \\
Alkol kullanma alışkanlı̆̆ı & Yok & $207(\% 82.5)$ \\
& Var & $93(\% 37.1)$ \\
Ailede kanser hikayesi varlığı & Yok & $158(\% 62.9)$ \\
& Eski kullanıcı & $42(\% 26.6)$ \\
Diş firçalama alışkanlığı & Var & $24(\% 9.6)$ \\
& Yok & $227(\% 90.4)$ \\
& Var & $103(\% 41)$ \\
& Yok & $147(\% 59)$ \\
& Evet & $232(\% 92.4)$ \\
& Günde 1 kez & $86(37.1)$ \\
& Günde 2 kez & $100(\% 43.1)$ \\
\hline & Haftada 1-2 kez & $31(13.7)$ \\
& Hayır & $19(\% 7.6)$ \\
\hline
\end{tabular}

Tablo 2. Katılımcıların ağız kanserinin risk faktörleri ile ilgili sorulara verdikleri cevapların dağılımı.

\begin{tabular}{|c|c|c|}
\hline \multirow[b]{2}{*}{ Risk faktörleri } & \multicolumn{2}{|c|}{ Cevap (Bilgi) } \\
\hline & Evet (\%) & Hayır (\%) \\
\hline Sigara kullanımı & $224(\% 89.2)$ & $27(\% 10.8)$ \\
\hline Alkol kullanımı & $192(\% 76.5)$ & $59(\% 23.5)$ \\
\hline $\begin{array}{l}\text { Uygun olmayan dental restorasyonlar (dolgu, } \\
\text { protez vs.) }\end{array}$ & $147(\% 58.6)$ & $104(\% 41.4)$ \\
\hline Human Papilloma Virüs & $155(61.2)$ & $96(\% 38.2)$ \\
\hline Sebze-meyveden fakir beslenme alışkanlığı & $132(\% 52.6)$ & $119(\% 47.4)$ \\
\hline $\begin{array}{l}\text { Bağışılklık sisteminin düşük olmasına neden } \\
\text { olan faktörler (AIDS vs.) }\end{array}$ & $200(\% 79.7)$ & $51(\% 20.3)$ \\
\hline Ailede ağız kanserine sahip bireyin varlığı & $179(\% 71.3)$ & $72(\% 28.7)$ \\
\hline Kötü ağız hijyeni & $211(\% 84.1)$ & $40(15.9)$ \\
\hline $\begin{array}{l}\text { Güneş ışınına maruz kalmak dudak kanserine } \\
\text { neden olup olamayacağı }\end{array}$ & $143(\% 57)$ & $108(\% 43)$ \\
\hline
\end{tabular}


Tablo 3. Katılımcıların ağız kanserinin belirtileri ile ilgili sorulara verdikleri cevapların dağılımı.

\begin{tabular}{lcc}
\hline & \multicolumn{2}{c}{ Cevap (Bilgi) } \\
\cline { 2 - 3 } Ağız Kanseri Belirtileri & Evet (\%) & Hayır (\%) \\
\hline Beyaz/ kırmızı yama şeklindeki lezyonlar & $199(\% 79.3)$ & $52(\% 20.7)$ \\
$\begin{array}{l}\text { Ağız içerisindeki anormal şişlik ya da kitle } \\
\text { şeklindeki lezyonlar }\end{array}$ & $210(\% 83.7)$ & $41(\% 16.3)$ \\
Iyileşmeyen ağız yaraları şeklindeki lezyonlar & $216(\% 86.1)$ & $35(\% 13.9)$ \\
Yutkunma ya da çiğnemede zorluk & $178(\% 70.9)$ & $73(\% 29.1)$ \\
\hline
\end{tabular}

Yaşla birlikte toplam bilgi düzeyi arasında ters yönlü anlamlı bir ilişki saptanmıştır $(p<0.05)$. Diş hekimi/doktorlardan ağız kanseri hakkında danışmanlık alan hastaların bilgi düzeyi yüksek bulunmuştur $(\mathrm{p}<0.05)$. Ailesinde kanser hikayesi olan hastaların bilgi düzeyi olmayan hastalarla karşılaştırıldığında anlamlı fark saptanmamıştır ( $>00.05)$. Sigara kullanmayan ve ağız bakımı iyi olan hastaların bilgi düzeyi daha yüksek olarak bulunmuştur. Sigaranın ağız kanseri yaptığı bilgisine sahip \%89.2 kat1lımcının \%33.5'inin sigara kullandığ 1 ve sigara içmenin ağız kanseri için risk faktörü olduğunu bilmelerine rağmen sigara içmeye devam ettikleri tespit edilmiştir. Aynı zamanda sigaranın ağız kanseri yaptığ bilgisine sahip katılımcilar içerisinde sigara kullanmayı bırakan grubun bilgi düzeyi, aktif sigara kullanan gruba göre daha yüksek olarak bulunmuştur $(\mathrm{p}<0.05)$. Kadın ve erkek cinsiyet gruplarında bilgi düzeyleri arasında anlamlı bir fark görülmemiştir $\quad(p>0.05)$. Eğitim seviyesi arttıkça bilgi düzeyinin arttığı görülmüştür. Ancak, istatistiksel anlamlılığa bakıldığında bu farkın ilkokul mezunu hastalar ile üniversite mezunları/yüksek lisans mezunları arasında olduğu bulunmuştur $(\mathrm{p}<0.05)$. Alkol kullanan hastaların kullanmayan hastalara göre alkolün ağız kanseri için risk faktörü oluşturduğu bilgisinin daha yüksek olduğu görülmüştür $(\mathrm{p}<0.05)$.

Katılımcıların \%85,7'si (n=215) "Sizce ağızda kanser oluşması mümkün müdür?" sorusuna evet cevabını vermiş, \%14,3'ü $\quad(n=36)$ mümkün olmayacağını ifade etmişlerdir. Ayrıca katılımcılara sorulan 'Çevrenizdeki diş hekimi ya da doktorlardan ağız kanseri ve risk faktörleri hakkında danışmanlık veya eğitim aldınız mı?' sorusuna \%88.9'u hayır, \%11.1'i evet cevabını vermiştir.

\section{Tartışma ve Sonuç}

Ağız kanserlerinin risk faktörleri ile ilgili sorulan sorulara verilen yanttlarda; Esen ve ark.'nın (9) yaptıkları çalışmada sigara $(\% 57.2)$ ve alkol (\%41.6) cevab1 en önde gelirken, Peker ve ark.'nın (10) yaptığ1 çalışmada sigara (\%57.6) ve alkol (27.9), Monteiro ve ark. (11) tarafindan yürütülen çalışmada sigara $(\% 89.5)$ ve alkol (\%63.3), Joseph ve ark.'nın (12) yayınında sigara $(\% 72.8)$ ve alkol (\%70.6) yine en çok doğru bilinen cevaplar olarak saptanmıştır. Bizim çalışmamızda ise; sigara (\%89.2) ve kötü ağız hijyeni (\%84.1) cevapları en çok doğru bilinmiştir.

Bilgi düzeyi ile yaş, cinsiyet ve eğitim düzeyleri arasında anlamlı ilişki varlığına bakıldığında Monteiro ve ark. (11) bir ilişki görememişken, Al-Maweri ve ark. (13) eğitim düzeyi yüksek bireylerin daha bilinçli olduğunu bulmuştur. Joseph ve ark. (12) ise kadınların daha bilinçli olduğunu ancak eğitim seviyesi ile bilgi düzeyi arasında bir ilişsi olmadığını bildirmiştir. Peker ve ark. (10) ise erkeklerin bilgi düzeyini daha yüksek olarak bildirmektedir. Bizim çalışmamızda ise yaşla birlikte bilgi düzeyinin azaldığı ve eğitim düzeyi arttıkça bilgi seviyesinin de arttığ1 görülmüştür. Kadın ve erkek bilgi seviyeleri arasında fark olmadığı bulunmuştur.

Saleh ve ark. (14) tarafindan yapilan çalışmada katılımcıların sadece \%4'ü ağız kanseri hakkındaki bilgi kaynağını diş hekimi olarak bildirmiştir. Bizim yaptığımız çalışmada ise \%11 katılımcı çevresindeki diş hekimlerinden ağız kanserleri hakkında danışmanlık aldığgnı bildirmektedir.

Ağı kanserinin erken belirtileri değerlendirildiğinde; Peker ve ark. (10) tarafindan yapılan çalışmada kırmızı 
görünümlü lekeler için $\% 6.5$, beyaz görünümlü lekeler için $\% 6.8$ ve iyileşmeyen ağız yaraları için \%17.5 olarak, Al-Maweri ve ark. (13) kırmızı görünümlü lekeler için $\% 26.1$, beyaz görünümlü lekeler için $\% 25.9$ ve iyileşmeyen ağız yaraları için \%31.9 olarak rapor etmiştir. Joseph ve ark. (12) ağızdaki kırmızı görünümlü lekeler için $\% 53.7$, beyaz görünümlü lekeler için $\% 43.4$ ve iyileşmeyen ağız yaraları için \%27.9 olarak bildirmiştir. Bizim yaptığımız çalışmada sorduğumuz sorular içerisinde en çok doğru bilinen ağız kanseri erken belirtileri ise; iyileşmeyen ağız yaraları (\%86.1) ve ağız içerisindeki anormal şişlik ya da kitle şeklindeki lezyonlar (\%83.7) şeklinde bulunmuştur.

Peker ve ark. (10) 2010 y1lında bir grup Türk populasyonunda yaptıkları çalışmada ağız kanseri farkındalık oranını \%39.3 olarak tespit etmiştir. Al-Maweri ve ark. (13) Suudi Arabistan'da yürüttüğü çalışmada ağız kanseri farkındalığını \%62.4, Monteiro ve ark. (11) 2012 y1linda Portekiz'de \%68.6, Srikanth Reddy ve ark. (15) Güney Hindistan'da yaptıkları çalışmada farkındalığı \%60.2, Hertrampf ve ark. (16) 2012 yilında Kuzey Almanya'da \%66 olarak bulmuştur. West ve ark. (17) 2006 yılında Büyük Britanya'da yaptıkları çalışmada ağı kanserinin farkındalığını \%95.6 olarak raporlamışlardır. $\mathrm{Bu}$ yüksek oranı medyada ağız kanseri bilinçlendirme haftasına gösterilen büyük ilgiyle ilişkilendirmişlerdir. Bizim yürüttüğümüz çalışmada ise; ağız kanseri farkındalığ $1 \% 85.7$ olarak bulunmuştur.

Risk faktörleri hakkında bilgi sahibi olmak, toplumda ağız kanserinin başarılı bir şekilde önlenmesinde en önemli parametrelerden biridir. Bu nedenle hastalar ağız kanserlerinin etiyolojik faktörleri ve belirtileri açısından bilgilendirilmeli, ağız kanserini önleyici adımlar atılmalıdır.

\section{KAYNAKLAR}

1. Torre, LA, Bray F, Siegel RL, Ferlay J, LortetTieulent J, Jemal, A. Global cancer statistics, 2012 CA: Cancer J Clin 2015;65:87-108.

2. Jemal A, Thomas A, Murray T, Thun, M. Cancer statistics, 2002 Ca-A Cancer J Clin 2002;52:2347.

3. Bettendorf O, Piffko J, Bankfalvi A. Prognostic and predictive factors in oral squamous cell cancer: important tools for planning individual therapy? Oral oncology 2004;40:110-9.

4. Pitiphat W, Diehl SR, Laskaris G, Cartsos V, Douglass CW, Zavras AI. Factors associated with delay in the diagnosis of oral cancer $J$ Dent Res. 2002;81:192-7.

5. Scully C. (2013) Oral and Maxillofacial Medicine. 3rd ed. Edinburgh: Elsevier.

6. Ram H, Sarkar J, Kumar H, Konwar R, Bhatt MLB, Mohammad S. Oral cancer: risk factors and molecular pathogenesis J Maxillofac Oral Surg. 2011;10:132-37

7. Neville BW, Allen CM, Damm DD, Chi AC. (2016) Oral and Maxillofacial Pathology. 4th ed. Canada: Elsevier.

8. Bruch JM, Treister NS. (2017). Oral Cancer In Clinical Oral Medicine and Pathology, Cham: Springer.

9. Esen A, Gürses G, Güler AY, Baştürk F. Ağız kanseri bilinç düzeyinin Türk hastalarda değerlendirilmesi Journal of Traditional Medical Complementary Therapies 2018;1:99-104.

10. Peker I, Alkurt M. Public awareness level of oral cancer in a group of dental patients J Contemp Dent Pract 2010;11:49-56.

11. Monteiro LS, Salazar F, Pacheco J, Warnakulasuriya S. Oral cancer awareness and knowledge in the city of Valongo, Portugal. Int $J$ Dent 2012;2012:1-8.

12. Joseph B, Ali M, Sundaram D. Awareness of mouth cancer among adult dental patients attending the Kuwait University Dental School Clinic J Cancer Educ 2018;33:340-5.

13. Al-Maweri S, Al-Soneidar $\mathrm{W}$, Dhaifullah E, Halboub E, Tarakji B. Oral cancer: Awareness and knowledge among dental patients in Riyadh $J$ Cancer Educ 2017;32:308-13.

14. Saleh A, Yang Y, Wan Abd Ghani W, Abdullah N, Doss J, Navonil R. Promoting oral cancer awareness and early detection using a mass media approac. Asian Pac J Cancer Prev 2012;13:121724.

15. Reddy BS, Doshi D, Reddy MP, Kulkarni S, Gaffar A, Reddy VR. Oral cancer awareness and knowledge among dental patients in South India Journal of Cranio-Maxillofacial Surgery 2012;40:521-4. 
16. Hertrampf K, Wenz H, Koller M, Wiltfang J. Public awareness about prevention and early detection of oral cancer: A population-based study in Northern Germany $J$ Craniomaxillofac Surg 2012;40:82-6.

17. West R, Alkhatib M, McNeill A, Bedi R. Awareness of mouth cancer in Great Britain $\mathrm{Br}$ Dent J 2006;200:167-9. 